\title{
Variation and Modal Characteristic of Tangential Threshing Cylinder Undergoing Threshing Dynamics
}

\author{
Zhong Tang $(\mathbb{D}$, Meilin Wang, Haotian Zhang, Yuepeng Zhou, and Yu Li \\ School of Agricultural Equipment Engineering, Jiangsu University, Zhenjiang 212013, Jiangsu, China \\ Correspondence should be addressed to Zhong Tang; tangzhong2012@126.com
}

Received 26 September 2019; Accepted 10 March 2020; Published 5 May 2020

Academic Editor: Arkadiusz Zak

Copyright ( 2020 Zhong Tang et al. This is an open access article distributed under the Creative Commons Attribution License, which permits unrestricted use, distribution, and reproduction in any medium, provided the original work is properly cited.

\begin{abstract}
During the rice-threshing process, straws always attached to a threshing cylinder and induced vibration and modal variation. In this paper, the constraint and threshing modals of the threshing cylinder were tested under idling and load conditions, and the causes of vibration and modal variation were explained. Based on the constraint and modal of the threshing cylinder, the vibration amplitudes and frequencies undergoing rice threshing were tested and analyzed. Results showed that mass of straws decreased gradually with the separation of rice grains and straws. And there was a nonuniform change in the circumferential resistance of the threshing cylinder. The fluctuating torque, speed, and frequencies during threshing process would cause vibration of the threshing cylinder. During rice-threshing process, the other natural frequencies were greater than the excitation frequency. With the accumulation of a large amount of straws, the threshing modal frequencies of the tangential threshing cylinder increased. The threshing bars caused vibration of the tangential threshing cylinder in the left and right direction mainly at two frequencies. At idling state of no-load, the vibration frequency $42.97 \mathrm{~Hz}$ of the tangential threshing cylinder in $X$ direction was close to the constraint modal frequency $41.58 \mathrm{~Hz}$. The eccentric load caused the excitation frequency to increase during the rice-threshing process. The vibration frequency was also closely related to the threshing modal. The tangential threshing cylinder with low vibration characteristics could be designed by using the eccentric vibration characteristics during the threshing process.
\end{abstract}

\section{Introduction}

Threshing cylinder is an important structural component of combine harvesters. When a combine harvester harvested crops, the straws attached to the threshing cylinder. Then, the threshing cylinder would be under a complex vibrational state. Especially for the tangential threshing cylinder undergoing rice-threshing process, rice straws on the circumference of the threshing cylinder had an eccentric effect. Eccentric load would appear on the circumference of the tangential threshing cylinder during rice-threshing process, which will cause the dynamic characteristics change of the threshing cylinder $[1,2]$. What are the characteristics of vibration and modal changes caused by the eccentric loading during rice threshing? This has attracted the attention and interest of many scholars $[3,4]$.

The load state of the threshing cylinder has been investigated many years ago [5]. The torque of threshing shaft during threshing process was studied by many researchers $[6,7]$. Axial-flow threshing power consumption at different operating factors was tested by Srison et al. [8]. He indicated that threshing power consumption was affected by threshing bars and the feeding rate. Indeed, the feeding rate during threshing is the direct factor determining the load, just as the vehicle's load directly determines the fuel consumption of the car. In order to analyze the characteristics of load and speed changes during threshing, Tang et al. developed a transverse multicylinder threshing test bench and tested the rotational speed at different rice-feeding rates [9]. The rotational speed of the threshing cylinder fluctuated within $\pm 3 \mathrm{rpm}$. The changes in speed and torque were an important feature of threshing cylinder vibration. Kang et al. derived mathematical relationship between the cylinder torque and the motor current, and a load control system was designed to keep the threshing load of the small-sized harvester in the rated load range [10]. Even at a stable feeding rate, the load 
and speed of the threshing cylinder are fluctuating and changing. According to existing reports, unstable feeding of crops is an important cause of changes in load and speed. However, there were fewer reports about the vibration of the threshing cylinder induced by the load fluctuating $[11,12]$.

Rotating cylinders similar to the rice-threshing cylinder have applications in many industrial machineries, such as blenders, impregnators, coaters, granulators, and cement mixers $[13,14]$. Research studies on the vibration of the rotating cylinder received extensive attention. Talamala et al. conducted an experiment to evaluate the performance and the cylinder vibration of an indirect diesel engine under eccentric load [15]. Koynov et al. measured the axial dispersion coefficient of powder in a rotating cylinder, and then particle motions in rotating cylinder were quantified as a function of process [16]. The vibration characteristics of the engine rotor and hydromechanical rotor in the disturbed state have been studied above. The external excitation has an important influence on the vibration characteristics of the rotor. At the same time, the vibration of the rotor will also increase the failure frequency of the entire machine. Bai and Zhang developed a stochastic hydraulic excitation model and tested the dynamic response of the shaft system of a hydroturbine set under stochastic hydraulic excitation. By analyzing the dynamic characteristics of the rotating rotor, the reliability and performance of the rotor and whole machine were greatly improved [17]. The rice-threshing cylinder has typical vibration characteristics during the ricethreshing process. The vibration begins at the beginning of threshing process and disappears with the end of threshing process. Vibration transients and instability make it difficult to analyze the vibration characteristics during the threshing process. The vibration characteristics during threshing process were dynamic and real time. The reasons for the vibration induced by threshing process were not only related to the state of the rice straw during threshing process but also to the cylinder excitation and response characteristics of the threshing cylinder itself.

Vibration of the threshing cylinder during the threshing process is influenced by the feed rice straw and the threshing process. In addition, there is a rubbing phenomenon during threshing process. Even if the threshing cylinder was originally dynamically balanced, the threshing bar will collide with the concave plate screen structure. The rubbing phenomenon during the rotation of the threshing cylinder causes great damage to the frame structure. Rubbing has occurred in many engineering fields. Rubbing is one of the most common and significant faults that exist in the rotor system. It exhibits extremely complicated dynamic behavior. A novel dynamic model of the rubbing rotor system was developed by Tang et al.. Based on the nonlinear rotor dynamic theory, its dynamic behavior with different parameters was analyzed [18]. Zhu et al. develops a dynamic model of a two-span rotor-bearing system with rubbing faults, and numerical simulation is carried out. Rotors running under normal condition, local slight rubbing, and severe rubbing throughout the entire cycle are simulated [19]. Dynamic trajectories and frequency spectrum diagrams are used to analyze the features of the rotor-bearing system with rub-impact faults under various parameters, and vibration characteristics of rub impact are obtained. During the rice-threshing process, the tangential threshing cylinder is only partially entangled by rice stalks. At this time, the tangential threshing cylinder is subjected to an eccentric load. The eccentric load of the tangential threshing cylinder is similar to the eccentric rotor on the motor [20]. The entanglement characteristics of the threshing cylinder were also changing as the grain continuously separated during the threshing process. Factors and variables induced vibration of the threshing cylinder during the threshing process, which has always restricted the dynamic design of the threshing cylinder.

Vibration caused by the rice-threshing process needed to be reduced, and obtaining the vibration characteristics of the threshing cylinder was an important prerequisite. Research studies on vibration of the threshing cylinder under the threshing state were in its infancy [21, 22]. There were few studies on parameters such as vibration amplitude, vibration frequency, and resonance phenomenon or constraint modal of the threshing cylinder during rice-threshing process. Controlling the vibration during threshing-process is also an important way to improve the reliability of the threshing cylinder. So, it is urgent to investigate the vibration of the threshing cylinder during the rice-threshing process. Unbalanced vibration identification of the tangential threshing cylinder has reported [23]. The vibration amplitude and frequency of the tangential threshing cylinder shaft and axial trajectory of the cylinder were tested. However, the vibration and modal change characteristics of the tangential threshing cylinder during threshing are not clear. The specific modal values before and after the tangential threshing cylinder are entangled with the stalk are of great significance to further reduce the threshing process vibration. In this paper, the constraint and threshing modals of the threshing cylinder were tested under idling and load conditions, and the causes of vibration and modal variation were explained.

\section{Materials and Methods}

2.1. Threshing Structure and Eccentric Load in Threshing Process. The threshing cylinder can thresh rice and separate grain from the concave sieve. The combine harvester with multiple threshing cylinders is a mainstream type. When rice is threshed, rice straws would attach to the threshing cylinder during the threshing process $[24,25]$. The diameters and lengths of the tangential threshing cylinder were 525 and $548 \mathrm{~mm}$, respectively. There are 6 rows of nail threshing bars evenly distributed on the circumference of the tangential threshing cylinder. The rotational speed was $700 \mathrm{rpm}$. The status and installation method of the tangential threshing cylinder under no straw flow is shown in Figure 1(a). During the rice threshing process, the rice straw is threshed between the lower part of the threshing cylinder and the concave plate sieve and is also transferred to the next working part. The straw flow and eccentric attached mass on the tangential threshing cylinder is shown in Figure 1(b). As the grains were threshed and separated, the mass of straws reduced gradually. And the mass of rice straws attached to the 


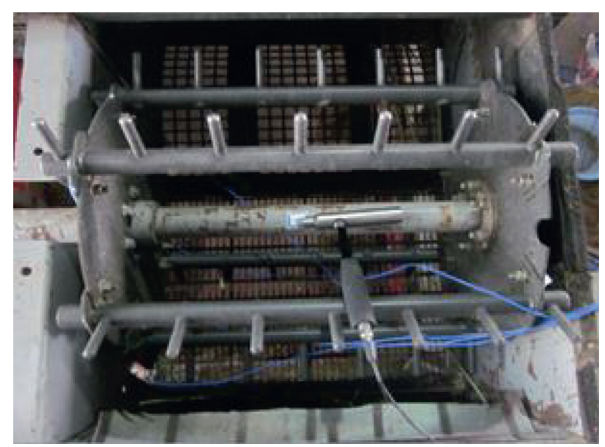

(a)

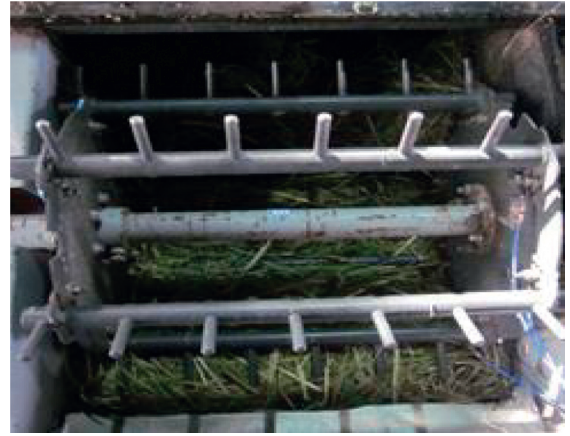

(b)

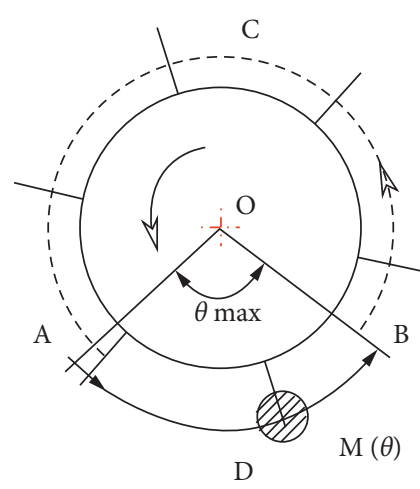

(c)

FIGURE 1: Threshing structure and eccentric mass of the tangential threshing cylinder. (a) Status and installation method under no straw flow. (b) Straw flow and eccentric attached mass. (c) Motion range of eccentric mass.

threshing cylinder decreased gradually. Then, rice straws attached to the tangential threshing cylinder formed the eccentric mass. The motion range of the eccentric mass is shown in Figure 1(c).

During the rice-threshing process, grains were separated from the concave screen. Then, the eccentric mass of rice straws decreased gradually. When the tangential threshing cylinder rotated at a high rotating speed, some of rice straws attached to the cylinder caused unbalanced vibration. The eccentric mass of rice straws attached to the threshing cylinder was equivalent to an unbalanced mass shown in Figure 1(c). Rice straws would not attach to the cylinder at arc ACB. However, rice straws attached to the cylinder at arc $\mathrm{ADB}$ and the mass of straws $M(\theta)$ decreased gradually from point A to point $\mathrm{B}\left(\theta\right.$ was 0 to $\left.100^{\circ}\right)$. Point $\mathrm{A}$ and $\mathrm{B}$ were the start and end points of the trajectory of the eccentric mass, respectively.

Rice-threshing vibration testing was carried out on the tangential threshing cylinder test bench. The grains were separated from the concave screen [9]. There were $4 \times 5$ boxes under the tangential threshing cylinder to receive the separated grains and short straws. Four lines of boxes were distributed along the tangential direction of the straw movement. Five rows of boxes were distributed along the axial direction of the tangential threshing cylinder. Then, the separated grains and short straws fell into the boxes. These testing methods and processes are shown in Figure 2.

\subsection{Constraint and Threshing Modal of Tangential Threshing} Cylinder. The modal of the tangential threshing cylinder was one vibration characteristic. The modal was natural attributes and features of eccentric vibration. There were two types of modals of the tangential threshing cylinder [26]. One type was the constraint modal, which was constrained by both ends of the drive shaft. The constraint modal of the tangential threshing cylinder is shown in Figure 1(a). Another type was the threshing modal, which was not only constrained by the both ends of the drive shaft but also constrained by the straws in threshing process. The threshing modal of the tangential threshing cylinder is shown in Figure 1(b).

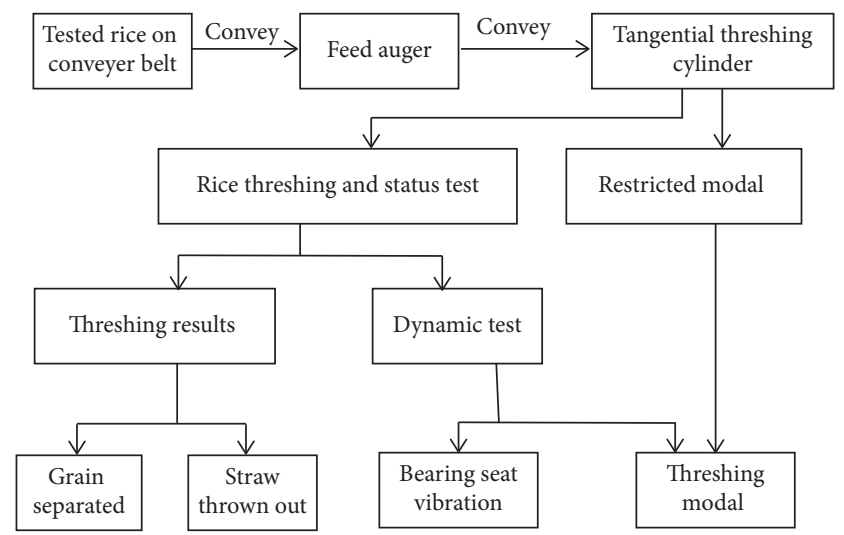

FIGURE 2: Testing methods and processes of vibration and modal characteristics.

The constraint modal of the tangential threshing cylinder was constrained by both ends of the drive shaft. There were only two constraints between the shaft and bearings without straws under the tangential threshing cylinder. The tangential threshing cylinder can easily rotate at low power. The constraint modal was under idling state of no-load. When the tangential threshing cylinder threshed rice, the threshing bars were bounded by the straws. Then, the tangential threshing cylinder modal was changed by the restrictions. When straws flowed under the tangential threshing cylinder, the threshing modal of the tangential threshing cylinder was changed. The threshing modal was under load state during rice-threshing process [27].

During rice-threshing process, the straws were propelled by threshing bars of the tangential threshing cylinder. Then, eccentric load was produced on the tangential threshing cylinder. The 3D model of the tangential threshing cylinder applied eccentric load constrained modal is shown in Figure 3(a).

The stresses and strains of the threshing cylinder and threshing bars were analyzed by the average threshing force of the threshing bars. Eccentric load forces were applied to the three-row threshing bars as shown in Figure 3(a). The rice straws attached to the cylinder and the center angle $\theta$ of 


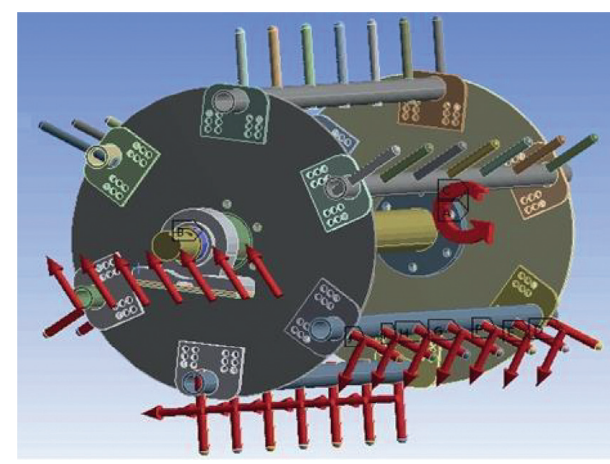

(a)

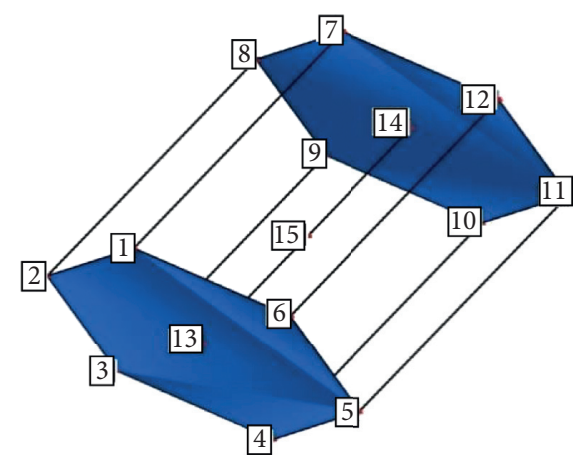

(b)

Figure 3: Model frame and vibration signal measuring points of the tangential threshing cylinder. (a) Applied eccentric load constrained modal. (b) Model frame of the tangential threshing cylinder.

the straws attached to the threshing cylinder was $0 \sim 100^{\circ}$. Only 3 rows of threshing bars were stressed during the ricethreshing process. To facilitate the determination of modal directions and vibration, a coordinate system was established on the tangential threshing cylinder. $X$ direction represented the flow direction of straws. $Y$ direction represented the axial direction of the tangential threshing cylinder. $Z$ direction represented the direction perpendicular to the XOY plane.

In order to analyze the constraint modal and threshing modal, the model structure of the tangential threshing cylinder was developed. Due to the small structure of the threshing bar, it has little effect on the mode of the threshing cylinder. Therefore, the effect of the threshing bar was ignored in the modal-modeling process. The frame with 15 points and two faces were used to simplify the modal of the tangential threshing cylinder. The model frame with 15 points is shown in Figure 3(b). If one of the points was struck by a hammer, the other points would have a vibration signal.

The criterion for the constraint modal and running modal of the tangential threshing cylinder was the modal assurance criterion (MAC) method. The criterion of the MAC was as follows:

$$
\mathrm{MAC}_{i j}=\frac{\left|\phi_{i}^{T} \phi_{j}\right|^{2}}{\phi_{i}^{T} \phi_{i} \phi_{j}^{T} \phi_{j}},
$$

where $\phi_{i}$ and $\phi_{j}$ were the vibration mode column vector and $i$ and $j$ were the modal order. The $i$ and $j$ were natural numbers.

The modal assurance criterion (MAC) was used to check the mutual independence and consistency between the twoorder modes. If the two-order modes of $\phi i$ and $\phi j$ were the same-order physical modes, the MAC value was 1 . If the two-order modes of $\phi i$ and $\phi j$ were not the same-order physical modes, or the $\phi i$ and $\phi j$ modal vectors were independent of each other, the value of MAC was equal to 0 . Due to the nonlinearity of structure and the external noise interference characteristics of the measured data in the actual test and analysis, the MAC minimum value 0.9 was considered to be the relevant mode. The value of MAC less than 0.05 was considered as the uncorrelated mode.

2.3. Testing Methods of Bearing Vibration. Since the cylinder shaft, bearing seat, and threshing bars were steel structures, the direct action point and excitation points were selected on the bearing seat. The vibration responses of the bearing seat can characterize vibration characteristics of the tangential threshing cylinder. Vibration test points of the bearing seat are shown in Figure 4. Because the tangential threshing cylinder was driven by a frequency conversion motor, the power was input by a belt reel. Vibration of both sides of the tangential threshing cylinder was tested. One side was coupling power transmission, which used coaxial drive to reduce the impact of vibration caused by different axes shown in Figure 4(a). The other side was the free end of the bearing seat shown in Figure 4(b). The vibration test methods of idling and load states were shown in [28]. The composition of the vibration signal acquisition system and signal analysis and processing system are shown in Figure 5.

Test performance parameters of the Chinese Donghua testing company's DH5902 dynamic signal acquisition instrument are shown in Table 1.

The signal acquisition system and dynamic signal acquisition instrument were produced by the Chinese Donghua testing company (DH5902 dynamic signal acquisition instrument). The signal acquisition system collected electrical signals of test points on the tangential threshing cylinder under 3 different conditions. The signal acquisition system used the United States of America (PCB) 356A16-type three-direction acceleration sensors.

The tangential threshing cylinder was driven by a frequency conversion motor. The power was input by a belt reel. A torque sensor, a rotational speed sensor, and two bearing seats were installed between the pulley and tangential threshing cylinder. The torque sensor and rotational speed sensor were HAD-CYB-803S (Beijing Westzh M \& E Technology Co., Ltd., China). The torque sensor and speed sensor could measure the torque and speed of the tangential 


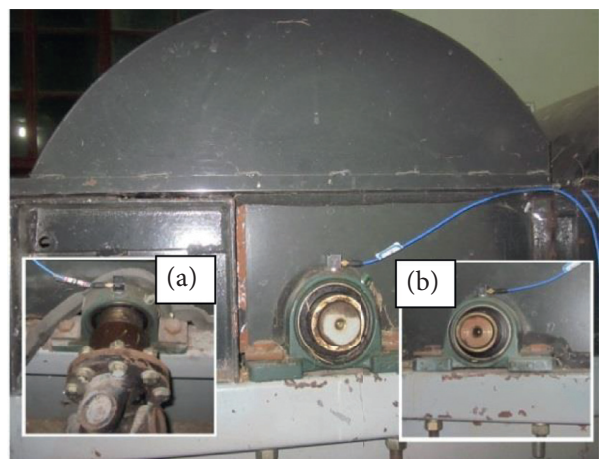

Figure 4: Vibration test of the bearing seat. (a) Coaxial drive of the bearing seat. (b) Free end of the bearing seat.

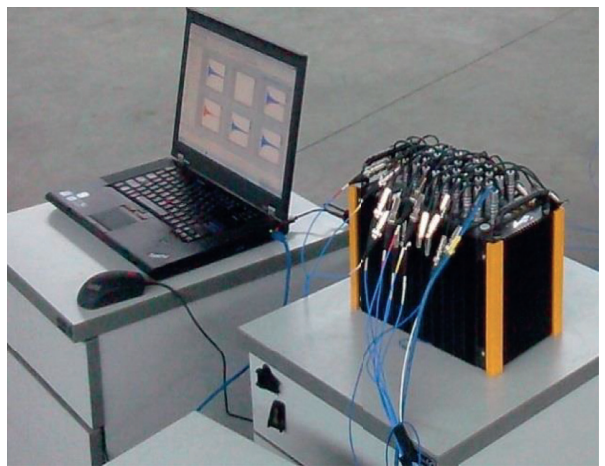

FIGURE 5: Signal acquisition system and dynamic signal acquisition instrument.

TABLE 1: Performance parameters of vibration test instruments.

\begin{tabular}{|c|c|c|c|}
\hline Equipment name & Performance index & Parameter values & Manufacturer \\
\hline Three-direction acceleration sensor of 356A16 & $\begin{array}{c}\text { Sensitivity } \\
\text { Frequency response } \\
\text { Range } \\
\text { Lateral sensitivity }\end{array}$ & $\begin{array}{c}100 \mathrm{mV}(\mathrm{g}) \\
0.3 \sim 6 \mathrm{KHz} \\
\pm 50 \mathrm{~g} \mathrm{pk} \\
<5 \%\end{array}$ & American Voltage Company (PCB) \\
\hline Dynamic signal acquisition instrument of DH5902 & $\begin{array}{c}\text { Channel } \\
\text { Sampling bandwidth } \\
\text { End scale value } \\
\text { Distortion factor }\end{array}$ & $\begin{array}{c}32 \\
16,100 \mathrm{KHz} \\
\pm 20 \mathrm{mv} \sim \pm 20 \mathrm{~V} \\
<0.5 \%\end{array}$ & Chinese Donghua testing company \\
\hline
\end{tabular}

threshing cylinder shaft, respectively. The measurement accuracy of the sensors was $0.25 \%$ of full-scale. And the frequency response time is $100 \mu \mathrm{s}$.

\section{Results and Discussion}

3.1. Rice Threshing and Straw Flow State. Freshly cut rice $(72 \mathrm{~kg}$ ) was placed on a $12 \mathrm{~m} \times 1 \mathrm{~m}$ conveyer belt running at $1 \mathrm{~m} / \mathrm{s}$ (the feeding rate of rice is $6 \mathrm{~kg} / \mathrm{s}$ ). The separated grains and short straws were received into the boxes under the tangential threshing cylinder. The received grains and short straws are shown in Figure 6.

Received grains and short straws under the tangential threshing cylinder are shown in Table 2.

Rice was threshed by the tangential threshing cylinder at a feeding speed of $6 \mathrm{~kg} / \mathrm{s}$. After 12 seconds, the total mass of the received grains and short straws under the tangential threshing cylinder was weighed. Then, the separated mass (grain and short straw flow) per second could be obtained by the total mass being divided into 12 seconds. Remained straw mass was the feeding mass minus the mass of separated grains and short straws. The remained straws mass along the tangential threshing cylinder is shown in Table 2.

According to Table 2, the mass of straws constantly changed during the threshing process. Remained straw mass along the tangential threshing cylinder reduced gradually. Straws flowed along the axial direction of the tangential threshing cylinder with a flow mass of $4.765 \sim 4.934 \mathrm{~kg} / \mathrm{s}$. Curves of feeding straw flow and remained straw flow along tangential direction are shown in Figure 7.

The central angle $\theta$ of rice straws attached to the tangential threshing cylinder was $0 \sim 100^{\circ}$. When the central angle $\theta$ was $0^{\circ}, 25^{\circ}, 50^{\circ}, 75{ }^{\circ}$ and $100^{\circ}$, the grains fell into the boxes 1, 2, 3, 4, and 5 below the threshing cylinder, 


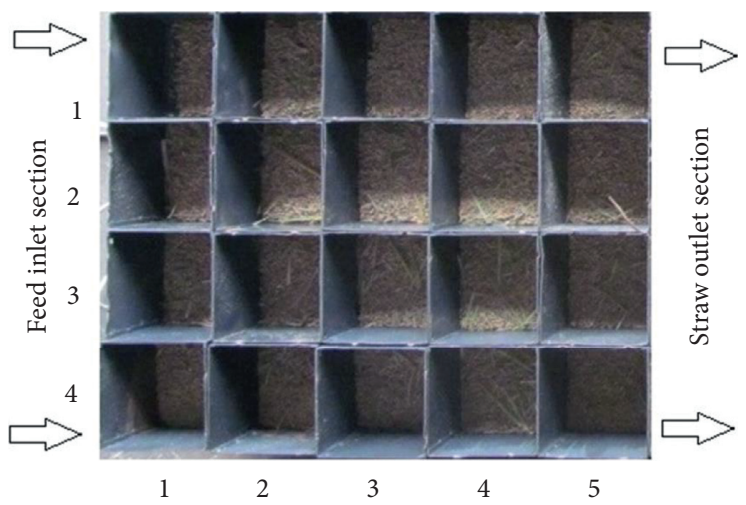

FIGURE 6: Received grains and short straws under the tangential threshing cylinder.

TABLE 2: Received grains and short straws under the tangential threshing cylinder.

\begin{tabular}{|c|c|c|c|c|c|c|c|}
\hline \multirow{2}{*}{ Box serial no. under cylinder } & \multicolumn{4}{|c|}{$\begin{array}{l}\text { Flow direction of } \\
\text { rice }(\mathrm{g})\end{array}$} & \multirow[t]{2}{*}{ Total mass (g) } & \multirow[t]{2}{*}{ Cumulative separated mass $(\mathrm{kg})$} & \multirow[t]{2}{*}{ Remained straw flow mass $(\mathrm{kg} / \mathrm{s})$} \\
\hline & 1 & 2 & 3 & 4 & & & \\
\hline 1 & 166 & 158 & 158 & 178 & 660 & 0.066 & 4.934 \\
\hline 2 & 128 & 130 & 134 & 132 & 524 & 0.118 & 4.882 \\
\hline 3 & 104 & 100 & 106 & 100 & 410 & 0.159 & 4.841 \\
\hline 4 & 82 & 88 & 90 & 102 & 362 & 0.196 & 4.804 \\
\hline 5 & 76 & 72 & 84 & 162 & 394 & 0.235 & 4.765 \\
\hline
\end{tabular}

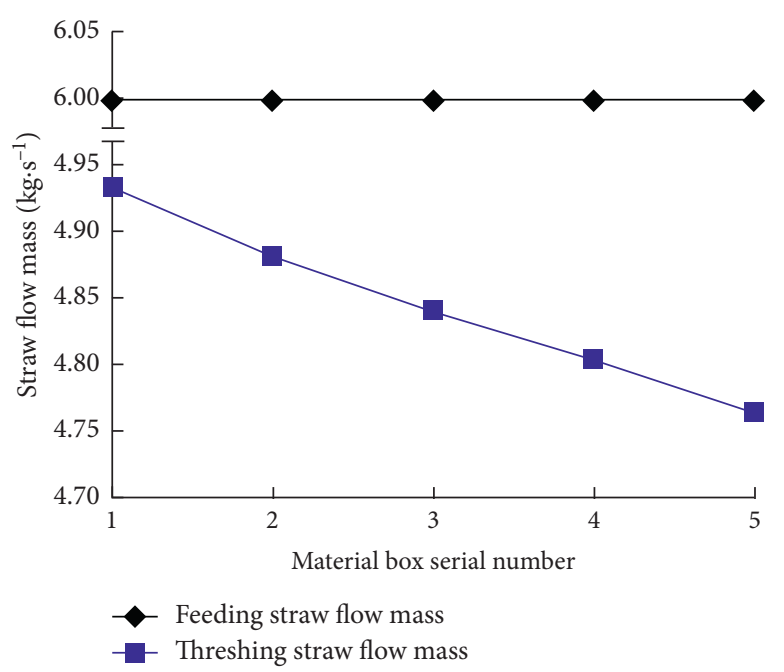

Figure 7: Curves of feeding straw flow and remained straw flow along the tangential direction.

respectively. As shown in equation (2), the straw flow rate in the axial direction of the tangential threshing cylinder was obtained by curve fitting:

$$
\mathrm{M}(\theta)=-0.0416 \theta+4.97,\left(0 \leq \theta \leq 100^{\circ}\right),
$$

where $M(\theta)$ was the flow mass of remained straw and $\theta$ was the central angle of rice straws attached to the threshing cylinder. The degree of correlation of the curve was $R^{2}=0.9953$.
Tang et al. conducted a variable mass test on the material flow rate of a tangential-longitudinal threshing and separation test-bed [29]. With the separation of grains during threshing process, the mass of rice straws gradually decreased. Then, the resistance on the circumference of the tangential- longitudinal cylinder changed unevenly. The eccentric load on the tangential-longitudinal cylinder changed unevenly. When rice was threshed by the tangential threshing cylinder, the torque and speed of the cylinder shaft were recorded by the HAD-CYB-803S torque and speed sensor. The actual threshing rotational speed of the tangential threshing cylinder was $698 \mathrm{rpm}$, so the rotational speed frequency was $11.63 \mathrm{~Hz}$. The fluctuation range was $2 \mathrm{rpm}$. The curve fluctuated up and down 7 times. The time intervals of the fluctuations were $0.4 \mathrm{~s}, 0.8 \mathrm{~s}$, and $1.2 \mathrm{~s}$, respectively. The fluctuation frequencies were $2.5 \mathrm{~Hz}, 1.25 \mathrm{~Hz}$, and $0.83 \mathrm{~Hz}$, respectively.

When rice straws attached to the threshing cylinder during threshing process, the rotational speed, torque signal, and power consumption fluctuated. The fluctuation could cause excitation force and vibration of the tangential threshing cylinder. So, rice straws attached to the threshing cylinder eccentrically. The eccentric load acted on the tangential threshing cylinder, which was the reason for vibration that emerged during rice-threshing process. When a driving torque acted on the cylinder shaft, the forces on threshing bars were the parts that balanced the driving torque [30]. The torque balance equation could be developed:

$$
T(t)=F(t) R,
$$


where $T(t)$ was the driving torque acting on the cylinder shaft, $F(t)$ was the load force on threshing bars, and $R$ was the rotation radius of straws.

Because the peak value of torque fluctuation was about $450 \mathrm{Nm}$, the threshing radius was the radius of the tangential threshing cylinder plus the length of half of the threshing bar, which was about $230 \mathrm{~mm}$. The load force on threshing bars was $652.17 \mathrm{~N}$ based on equation (3). There were 3 rows of threshing bars were forced in the rice-threshing process. And each row of threshing bars was forced as $217.39 \mathrm{~N}$. There were 7 threshing bars on every row. So, load force on every threshing bar was $31.06 \mathrm{~N}$.

There was a functional relationship among the eccentric force, rotational speed, and eccentric mass. Functional relationship is shown as follows:

$$
F(t)=M(\theta) R \omega^{2},
$$

where $F(t)$ was the eccentric force on threshing bars, $R$ was the rotation radius of straws, and $M(\theta)$ was eccentric mass of straws attached to threshing bars.

The eccentric mass induced by threshing bars could be calculated by equation (4). The eccentric mass attached to each row of threshing bars was $1.35 \mathrm{~kg} / \mathrm{s}$. The total eccentric mass attached to 3 rows of threshing bars was $4.05 \mathrm{~kg} / \mathrm{s}$. According to Table 2, the remained straw mass in the tangential threshing cylinder was $4.934 \sim 4.765 \mathrm{~kg} / \mathrm{s}$. The difference between remained straw mass and eccentric mass showed that only part of straws mass not attached to threshing bars. The total eccentric mass attached to 3 rows of threshing bars was less than the remained straws mass because some straw mass attached to the grid concave.

\subsection{Constraint Modal and Threshing Modal with Eccentric} Load. During rice-threshing process, the rice straw attached to the threshing cylinder would cause modal change of the tangential threshing cylinder. The modal was an influencing factor of threshing cylinder vibration. The constraint modal and threshing modal were analyzed by the Chinese Donghua testing company's DH5902 dynamic signal acquisition instrument.

Because tangential threshing cylinder was axisymmetric and centrosymmetric, vibration responses of the two end faces were essentially the same. And the vibration responses of six points on each end face were also essentially the same. Point 1 on the frame could be used to respond the frequency. The analysis results also proved that frequency response curves of all points were the same. Frequency responses of the tangential threshing cylinder at constraint and threshing states are shown in Figure 8.

According to Figure 8, there is some different response sensitivity between the frequency responses of the constraint modal and threshing modal. When there were straws between the grid concave and cylinder, the frequency responses reduced significantly. The 12 orders of the constraint modal and threshing modal were calculated separately. Modal values of the constraint modal and threshing modal are shown in Table 3.
As shown in Table 3, the constraint modal and threshing modal values of 12 orders were not corresponding one by one. The first-order constraint modal was $41.58 \mathrm{~Hz}$, but the corresponding first-order threshing modal was $42.88 \mathrm{~Hz}$. The 2nd, 4 th, and 11th order constraint modals were different to corresponding threshing modals. The above 3 orders of threshing modal were scattered. So, the threshing modal increased slightly compared to the corresponding constraint modal. When the excitation frequency was close to the natural frequency of the tangential threshing cylinder, the tangential threshing cylinder would produce resonance.

The fluctuation frequencies of speed were $2.5 \mathrm{~Hz}$, $1.25 \mathrm{~Hz}$, and $0.83 \mathrm{~Hz}$, respectively. The threshing rotational frequency was $11.63 \mathrm{~Hz}$. All of the fluctuation frequencies and threshing rotational frequency were less than the 1st constraint modal $(41.58 \mathrm{~Hz})$ and threshing modal $(42.88 \mathrm{~Hz})$. The intrinsic frequencies were more than the excitation frequency. The rotational speed frequency and fluctuation frequencies would not cause the resonance phenomenon [31].

Constraint modal values of 12 serials and threshing modal values of 15 serials were calculated by the Chinese Donghua testing company's DH5902 dynamic signal acquisition instrument. Modal distribution and response sensitivity of the tangential threshing cylinder are shown in Figure 9.

According to Figure 9, when the excitation frequency was equal to natural frequency, response sensitivity of the tangential threshing cylinder was 1 . Then, resonance phenomenon was appeared, the shaft vibration would increase dramatically. The height of the column represented the degree of response sensitivity, and the maximum response was 1. Columnar color could also reflect this response sensitivity. The response sensitivity level of constraint modal frequency at different excitation frequencies is shown in Table 4.

The response sensitivity level of threshing modal frequency at different excitation frequencies is shown in Table 5.

Because the fluctuation frequencies of threshing speed were $2.5 \mathrm{~Hz}, 1.25 \mathrm{~Hz}$, and $0.83 \mathrm{~Hz}$, and the threshing speed frequency was $11.63 \mathrm{~Hz}$. As shown in Tables 4 and 5, all these fluctuation frequencies and threshing speed frequency were less than the 1st intrinsic constraint frequency constraint modal $(41.58 \mathrm{~Hz})$ and threshing modal $(42.88 \mathrm{~Hz})$. Other intrinsic constraint frequencies were more than the incentive frequency in rice-threshing process. The rotation speed frequency, threshing speed frequency, and fluctuation frequencies would not cause the resonance phenomenon. The tangential threshing cylinder rotated at high speed under the working condition. The modal of the fluid machinery rotor was similar to the modal of the threshing cylinder [32]. Working modals of rotors have been studied in numerous industrial fields. Chen et al. analyzed the modal change rule of the axial-flow pump rotor system in water [33]. The tangential threshing cylinder modal was changed by adding straw to the cylinder. The modal increased with the increase of the straw mass attached to the cylinder circumference. 


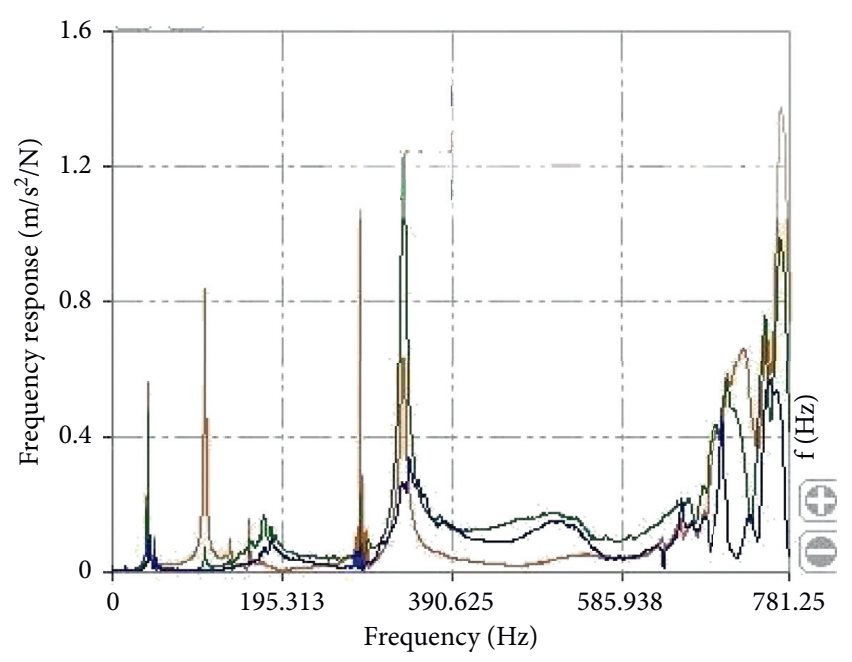

AI1-13_AI1-01 (X) $\left(\mathrm{m} / \mathrm{s}^{2} / \mathrm{N}\right)$

AI1-13_AI1-02 (Y) $\left(\mathrm{m} / \mathrm{s}^{2} / \mathrm{N}\right)$

AI1-13_AI1-03 (Z) $\left(\mathrm{m} / \mathrm{s}^{2} / \mathrm{N}\right)$

(a)

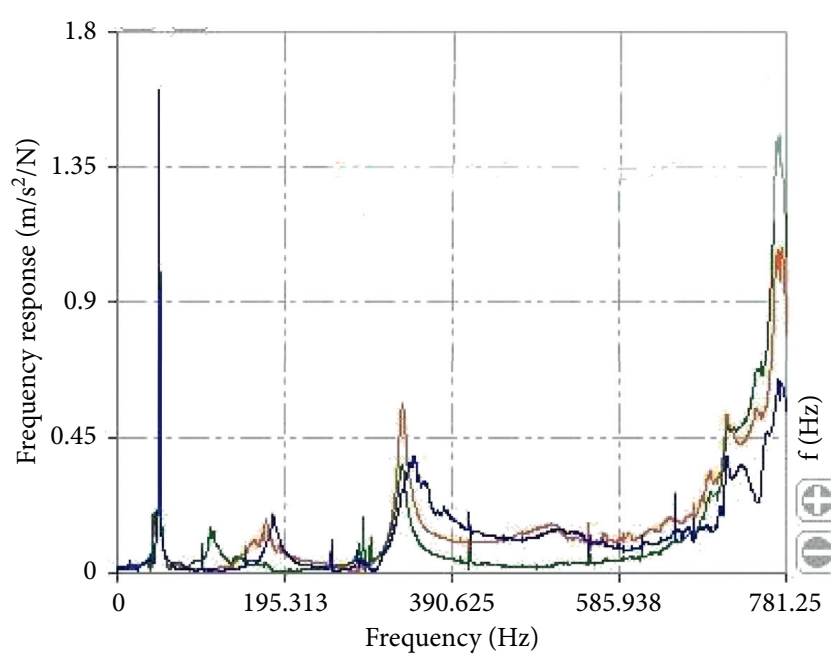

AI1-13_AI1-01 (X) $\left(\mathrm{m} / \mathrm{s}^{2} / \mathrm{N}\right)$

AI1-13_AI1-02 (Y) $\left(\mathrm{m} / \mathrm{s}^{2} / \mathrm{N}\right)$

AI1-13_AI1-03 $(\mathrm{Z})\left(\mathrm{m} / \mathrm{s}^{2} / \mathrm{N}\right)$

(b)

Figure 8: Frequency responses of the tangential threshing cylinder at constraint and threshing states. (a) Constraint modal. (b) Threshing modal.

TABle 3: Modal values of constraint modal and threshing modal.

\begin{tabular}{lcc}
\hline $\begin{array}{l}\text { Modal serial } \\
\text { number }\end{array}$ & $\begin{array}{c}\text { Constraint modal } \\
(\mathrm{Hz})\end{array}$ & $\begin{array}{c}\text { Threshing modal } \\
(\mathrm{Hz})\end{array}$ \\
\hline 1 & 41.58 & 42.88 \\
& & 109.13 \\
2 & 107.48 & 113.06 \\
& & 135.11 \\
3 & 150.50 & \\
4 & 158.16 & 160.99 \\
5 & 179.24 & 174.26 \\
6 & 201.28 & 183.15 \\
7 & 278.85 & 221.23 \\
8 & 294.19 & 283.35 \\
9 & 306.75 & 300.68 \\
10 & 335.29 & 331.98 \\
& & 343.98 \\
11 & 345.29 & 360.18 \\
& & 383.69 \\
12 & 401.12 & 398.34 \\
\hline
\end{tabular}

3.3. State of Vibration Amplitude and Frequency in Threshing Process. Bearing seat vibration was tested by (PCB) 356A16type three-direction acceleration sensors and recorded by the DH5902 dynamic signal acquisition instrument. Then, the vibration amplitude and frequency of the tangential threshing cylinder shaft were used to evaluate the vibration state of threshing dynamics. The vibration responses of bearing seat can characterize vibration characteristics of the tangential threshing cylinder. Vibration of both sides of the tangential threshing cylinder was tested. One side was coupling power transmission, which used coaxial drive to reduce the impact of vibration caused by different axes shown in Figure 4(a). The other side was the free end of the bearing seat shown in Figure 4(b). The $X$ direction represented the flow direction of straws. The $Y$ direction represented the axial direction of the tangential threshing cylinder. The $Z$ direction represented the direction perpendicular to the $X O Y$ plane.

Ferfecki et al. confirmed that vibration amplitude and frequency of the bearing seat were used to reveal the vibration state of the rotor [34]. Time-domain vibration and trequency-domain vibration were used to analysis the threshing dynamics.

3.3.1. Time-Domain Vibration Analysis. The idling state of no-load and load state of threshing process were two states of the tangential threshing cylinder. Both ends of the tangential threshing cylinder were supported by the bearing seat. Figure 4(a) shows the free end of the bearing seat. The other side was the bearing seat with coaxial drive. Figure 4(b) shows the coaxial drive of the bearing seat.

During the rice-threshing process, the bearing seat vibration was measured by acceleration sensors. The vibration signals of the bearing seat were recorded as time-domain function $[35,36]$. In order to analysis the threshing dynamics of the tangential threshing cylinder, the time-domain functions of the bearing seat with coaxial drive under idling state are shown in Figure 10.

The time-domain functions of the bearing seat with coaxial drive under threshing state are shown in Figure 11.

According to Figures 10 and 11, all vibration amplitudes of the tangential threshing cylinder changed. $X$ direction represented the flow direction of straws. The vibration amplitude of $X$ direction changed slightly. The vibration amplitude under threshing state increased slightly greater than under idling state. The same results were also obtained in the $Z$ direction. 

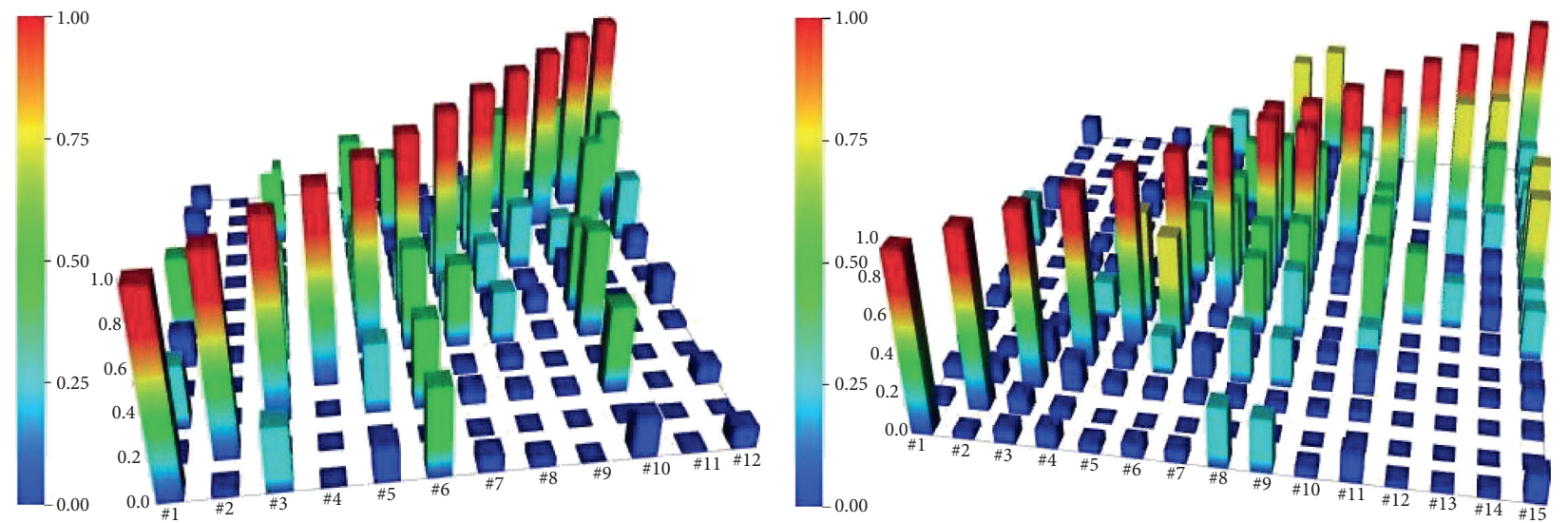

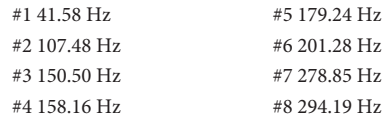

(a)

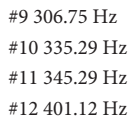

\#12 401.12 Hz

\begin{abstract}
\#1 $42.88 \mathrm{~Hz}$
$\# 2109.13 \mathrm{~Hz}$

\#3 $113.06 \mathrm{~Hz}$

\#4 $135.11 \mathrm{~Hz}$

\#5 $160.99 \mathrm{~Hz}$
\end{abstract}

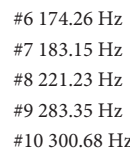

FIgURE 9: Modal distribution and vibration response sensitivity of the tangential threshing cylinder. (a) Constraint modal. (b) Threshing modal.

TABLE 4: Response sensitivity level of restricted modality frequency at different excitation frequencies.

\begin{tabular}{lcccccccccccc}
\hline \multirow{2}{*}{ Frequency } & \multicolumn{10}{c}{ Excitation frequency response (response sensitivity level was $0-1)$} \\
& 41.58 & 107.48 & 150.50 & 158.16 & 179.24 & 201.28 & 278.85 & 294.19 & 306.75 & 335.29 & 345.29 & 401.12 \\
\hline 41.58 & 1 & 0.03 & 0.33 & 0.01 & 0.18 & 0.45 & 0.08 & 0.04 & 0.01 & 0.2 & 0.02 & 0.1 \\
107.48 & 0.03 & 1 & 0 & 0 & 0.02 & 0 & 0 & 0 & 0 & 0.02 & 0 & 0 \\
150.50 & 0.33 & 0 & 1 & 0 & 0.36 & 0.46 & 0.07 & 0.05 & 0.02 & 0.45 & 0.01 & 0.1 \\
158.16 & 0.01 & 0 & 0 & 1 & 0.05 & 0.01 & 0.03 & 0.07 & 0.01 & 0.02 & 0.01 & 0 \\
179.24 & 0.18 & 0.02 & 0.36 & 0.05 & 1 & 0.55 & 0.44 & 0.28 & 0.03 & 0.57 & 0.01 & 0.04 \\
201.28 & 0.45 & 0 & 0.46 & 0.01 & 0.55 & 1 & 0.22 & 0.11 & 0.1 & 0.47 & 0.04 & 0.17 \\
278.85 & 0.08 & 0 & 0.07 & 0.03 & 0.44 & 0.22 & 1 & 0.29 & 0.06 & 0.17 & 0.01 & 0.02 \\
294.19 & 0.04 & 0 & 0.05 & 0.07 & 0.28 & 0.11 & 0.29 & 1 & 0.36 & 0.28 & 0.14 & 0.16 \\
306.75 & 0.01 & 0 & 0.02 & 0.01 & 0.03 & 0.1 & 0.06 & 0.36 & 1 & 0.04 & 0.58 & 0.36 \\
335.29 & 0.2 & 0.02 & 0.45 & 0.02 & 0.57 & 0.47 & 0.17 & 0.28 & 0.04 & 1 & 0 & 0.06 \\
345.29 & 0.02 & 0 & 0.01 & 0.01 & 0.01 & 0.04 & 0.01 & 0.14 & 0.58 & 0 & 1 \\
401.12 & 0.1 & 0 & 0.1 & 0 & 0.04 & 0.17 & 0.02 & 0.16 & 0.36 & 0.06 & 0.53 \\
\hline
\end{tabular}

TABLE 5: Response sensitivity level of threshing modality frequency at different excitation frequencies.

\begin{tabular}{lccccccccccccccc}
\hline \multirow{2}{*}{ Frequency } & \multicolumn{10}{c|}{ Excitation frequency response (response sensitivity level was $0-1$ ) } \\
& 42.88 & 109.13 & 113.06 & 135.11 & 160.99 & 174.26 & 183.15 & 221.23 & 283.35 & 300.68 & 331.98 & 343.98 & 360.18 & 383.69 & 398.34 \\
\hline 42.88 & 1 & 0.04 & 0.08 & 0.10 & 0.05 & 0.07 & 0.07 & 0.33 & 0.30 & 0.06 & 0.16 & 0.03 & 0.03 & 0.04 & 0.16 \\
109.13 & 0.04 & 1 & 0.11 & 0.06 & 0 & 0 & 0 & 0.01 & 0.02 & 0 & 0.03 & 0 & 0 & 0 & 0.01 \\
113.06 & 0.08 & 0.11 & 1 & 0.18 & 0.07 & 0.06 & 0.07 & 0.08 & 0.06 & 0.04 & 0.06 & 0 & 0 & 0.01 & 0.03 \\
135.11 & 0.10 & 0.06 & 0.18 & 1 & 0.09 & 0.22 & 0.19 & 0.31 & 0.28 & 0.03 & 0.19 & 0.02 & 0.11 & 0.04 & 0.12 \\
160.99 & 0.05 & 0 & 0.07 & 0.09 & 1 & 0.66 & 0.01 & 0.07 & 0.06 & 0.07 & 0.24 & 0.05 & 0 & 0 & 0.07 \\
174.26 & 0.07 & 0 & 0.06 & 0.22 & 0.66 & 1 & 0.08 & 0.44 & 0.39 & 0.01 & 0.58 & 0.01 & 0.02 & 0.06 & 0.29 \\
183.15 & 0.07 & 0 & 0.07 & 0.19 & 0.01 & 0.08 & 1 & 0.51 & 0.54 & 0.03 & 0.10 & 0.43 & 0.27 & 0.15 & 0.28 \\
221.23 & 0.33 & 0.01 & 0.08 & 0.31 & 0.07 & 0.44 & 0.51 & 1 & 0.97 & 0.12 & 0.57 & 0.09 & 0.10 & 0.15 & 0.67 \\
283.35 & 0.3 & 0.02 & 0.06 & 0.28 & 0.06 & 0.39 & 0.54 & 0.97 & 1 & 0.14 & 0.54 & 0.11 & 0.12 & 0.18 & 0.76 \\
300.68 & 0.06 & 0 & 0.04 & 0.03 & 0.07 & 0.01 & 0.03 & 0.12 & 0.14 & 1 & 0.10 & 0.08 & 0.28 & 0.33 & 0.22 \\
331.98 & 0.16 & 0.03 & 0.06 & 0.19 & 0.24 & 0.58 & 0.10 & 0.57 & 0.54 & 0.10 & 1 & 0.01 & 0.07 & 0.13 & 0.38 \\
343.98 & 0.03 & 0 & 0 & 0.02 & 0.05 & 0.01 & 0.43 & 0.09 & 0.11 & 0.08 & 0.01 & 1 & 0.77 & 0.51 & 0.15 \\
360.18 & 0.03 & 0 & 0 & 0.01 & 0 & 0.02 & 0.27 & 0.10 & 0.12 & 0.28 & 0.07 & 0.77 & 1 & 0.72 & 0.25 \\
383.69 & 0.04 & 0 & 0.01 & 0.04 & 0 & 0.06 & 0.15 & 0.15 & 0.18 & 0.33 & 0.13 & 0.51 & 0.71 & 1 & 0.32 \\
398.34 & 0.16 & 0.01 & 0.03 & 0.12 & 0.07 & 0.29 & 0.28 & 0.67 & 0.76 & 0.22 & 0.38 & 0.15 & 0.25 & 0.32 & 1 \\
\hline
\end{tabular}




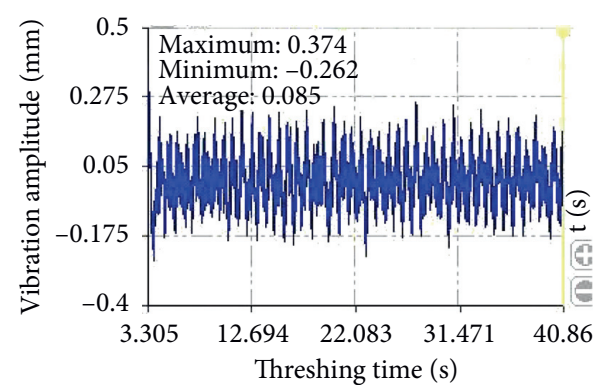

- AI1-04_TwoIntegral (mm)

(a)

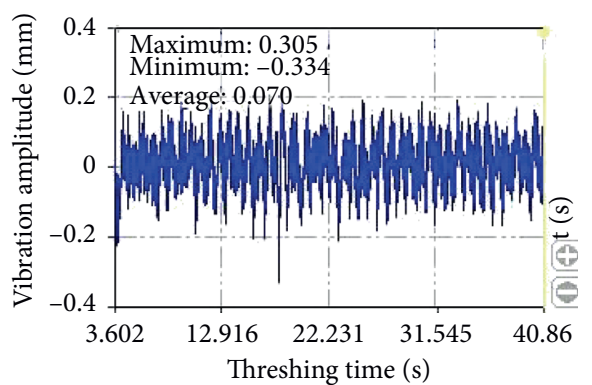

- AI1-05_TwoIntegral (mm)

(b)

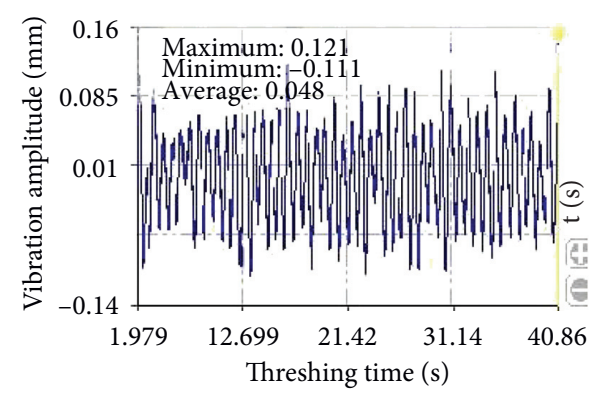

AI1-06_TwoIntegral (mm)

(c)

Figure 10: Time-domain functions of the bearing seat with coaxial drive under idling state. (a) $X$ direction. (b) $Y$ direction. (c) $Z$ direction.

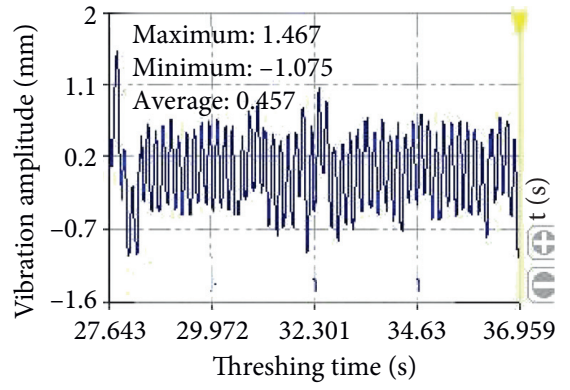

AI1-04_TwoIntegral (mm)

(a)

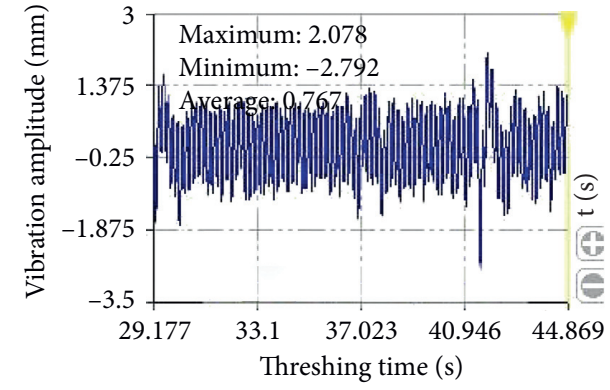

AI1-05_TwoIntegral (mm)

(b)

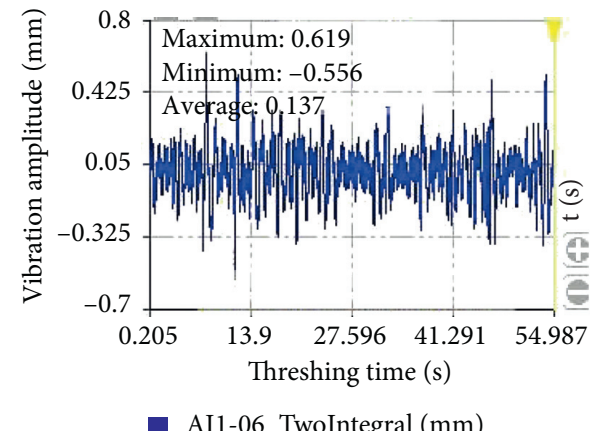

(c)

Figure 11: Time-domain functions of the bearing seat with coaxial drive under threshing state. (a) $X$ direction. (b) $Y$ direction. (c) $Z$ direction. 
TABLE 6: Vibration amplitudes of the free end of the bearing seat under idling state and threshing state.

\begin{tabular}{lcccccc}
\hline Vibration amplitude types & \multicolumn{2}{c}{$\begin{array}{c}\text { Vibration amplitude in } X \\
\text { direction }(\mathrm{mm})\end{array}$} & \multicolumn{2}{c}{$\begin{array}{c}\text { Vibration amplitude in } Y \\
\text { direction }(\mathrm{mm})\end{array}$} & \multicolumn{2}{c}{$\begin{array}{c}\text { Vibration amplitude in } Z \\
\text { direction }(\mathrm{mm})\end{array}$} \\
& Idling state & Threshing state & Idling state & Threshing state & $\begin{array}{c}\text { Idling state } \\
\text { Threshing state }\end{array}$ \\
\hline Maximum & 0.060 & 0.077 & 0.393 & 8.779 & 0.119 & 0.721 \\
Minimum & -0.049 & 0.116 & -0.271 & -6.966 & -1.05 & -0.603 \\
Average & 0.013 & 0.012 & 0.060 & 1.640 & 0.040 & 0.123 \\
\hline
\end{tabular}

The vibration amplitudes of the free end of the bearing seat under idling state and threshing state are shown in Table 6.

As shown in Table 6 and Figures 10 and 11, the vibration amplitude of the free end of the bearing seat in $X$ direction increased more obvious than the bearing seat with coaxial drive. In rice-threshing state, the vibration amplitude in $X$ direction increased by about 6 times. And the vibration amplitude in $Y$ direction increased by about 24 times. As shown in Figure 11, the vibration amplitude in $Y$ direction was induced by distribution of the threshing bars. In analyzing the vibration at both ends of the long shaft, torsional vibration often occurs at both ends. It is mainly caused by the speed difference between the two ends of the shaft during the rotation [37]. In this paper, the amplitude of the shaft end vibration was analyzed. So, the speed difference between the two ends of the threshing drum is not considered.

When the tangential threshing cylinder rotated, rice straws were fed and drained by threshing bars. The feeding and draining direction of rice straw is shown in Figure 12. Threshing bars were not distributed on the same circumference and the cylinder shaft would sway from side to side with the movement of straws.

By comparing the vibration amplitude of the free end of the bearing seat and bearing seat with coaxial drive in $Y$ direction, it was found that the vibration amplitude increment of the bearing seat with coaxial drive was not as obvious as the vibration amplitude increment of the free end of the bearing seat. The reason for this phenomenon was that the coaxial drive of the bearing seat limited the shaft vibration.

3.3.2. Frequency-Domain Vibration Analysis. The frequency-domain vibration signals could be obtained based on the time-domain vibration signals of the tangential threshing cylinder. In order to obtain the frequency-domain characteristic of the tangential threshing cylinder with coaxial drive under idling state and threshing state, the frequency cloud of vibration time with coaxial drive and the free end were calculated by the Chinese Donghua testing company's DH5902 dynamic signal acquisition instrument. Because the frequency cloud is used to express the frequency and amplitude of vibration along time, the colours in the frequency cloud from blue to red are a change trend from 0 to the maximum amplitude. Red represents the maximum value in this vibration test. Frequency cloud of vibration time with coaxial drive under idling state is shown in Figure 13.

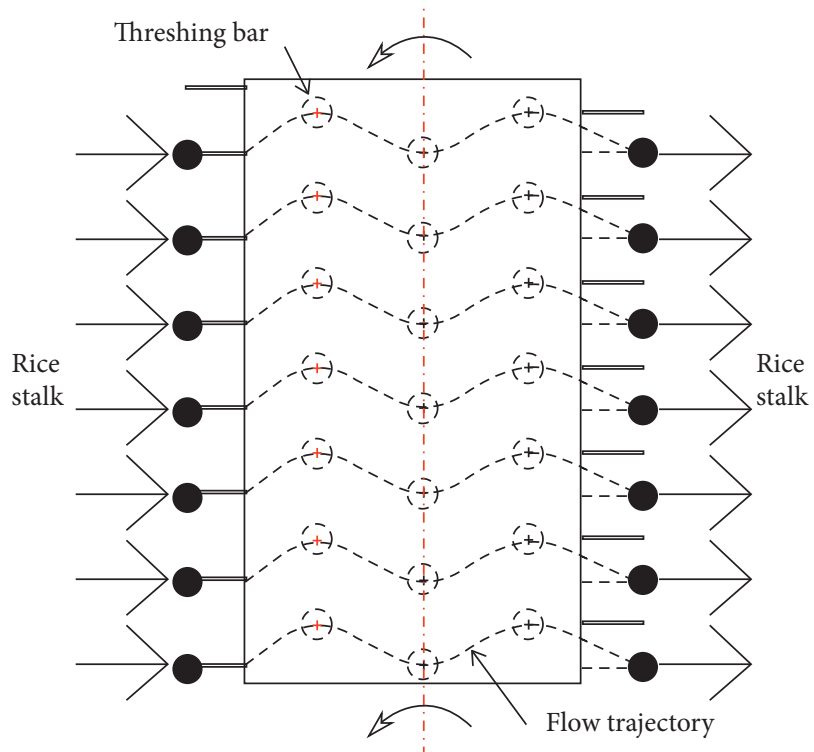

FIGURE 12: Feeding and draining direction of the rice stalk induced by distribution of threshing bars.

With the same method, frequency cloud of vibration time with coaxial drive under threshing state is shown in Figure 14.

It is known by comparison that the vibration amplitude in $Y$ direction is bigger than that of $X$ direction and $Z$ direction under idling state. The vibration amplitude of coaxial drive was bigger than that of the free end of the tangential threshing cylinder under idling state. Vibration amplitude of coaxial drive under threshing state is bigger than the free end under threshing state. At the same time, vibration amplitude of threshing state is bigger than that of idling state. So, the frequency-domain vibration signals of the bearing seat with coaxial drive under idling state and vibration signals of the bearing seat with coaxial drive under threshing state were used for frequency-domain analysis.

Frequency-domain vibration signals of the bearing seat with coaxial drive under idling state are shown in Figure 15.

Frequency-domain vibration signals of the bearing seat with coaxial drive under threshing state are shown in Figure 16. The six frequencies which had greater contribution to the vibration are shown in the figures.

As shown in Figures 15 and 16, the vibration frequencies of the tangential threshing cylinder had a common value in $X$ direction, $Y$ direction, and $Z$ direction. According to Figures 15 and 16, the main excitation frequencies in $X$ direction were $13.672 \mathrm{~Hz}$ and $152.344 \mathrm{~Hz}$. These two 


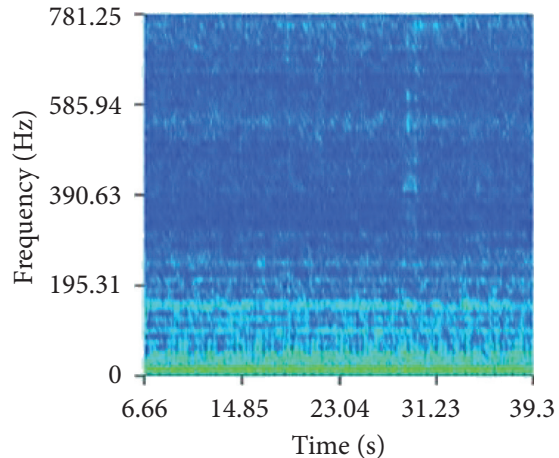

(a)

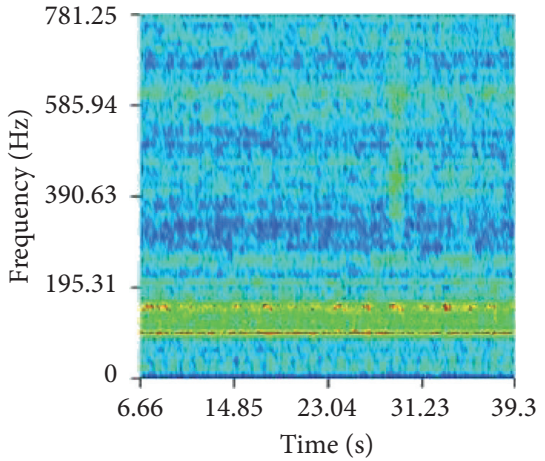

(b)

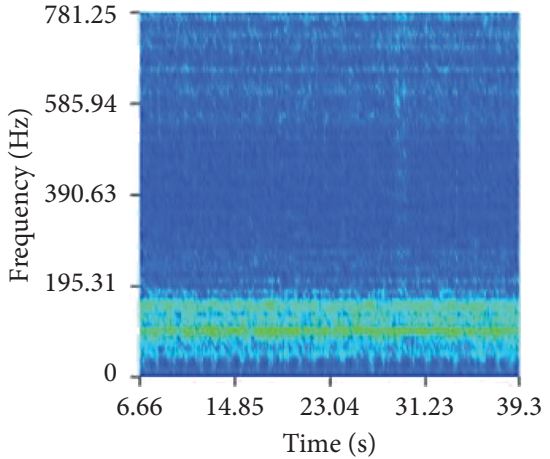

(c)

Figure 13: Frequency cloud of vibration time with coaxial drive under idling state. (a) $X$ direction. (b) $Y$ direction. (c) $Z$ direction.

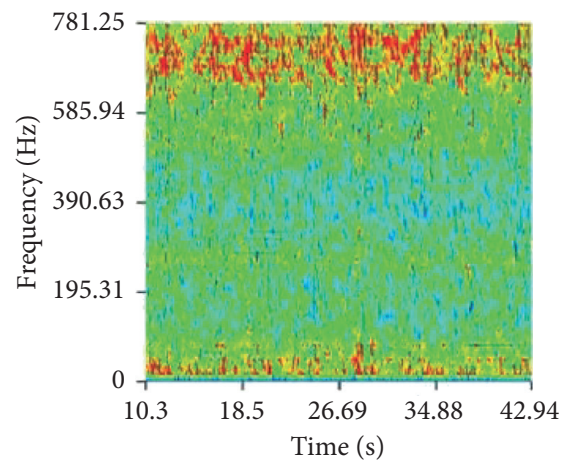

(a)

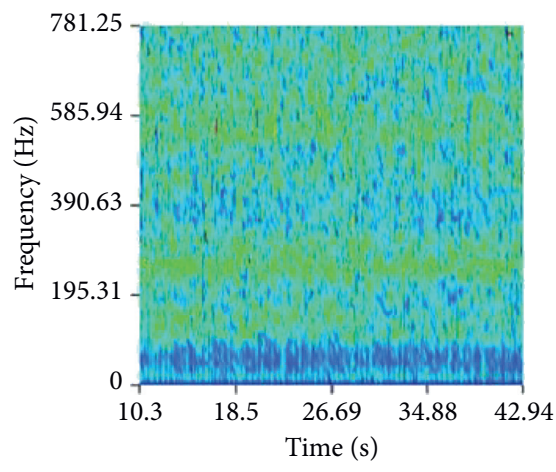

(b)

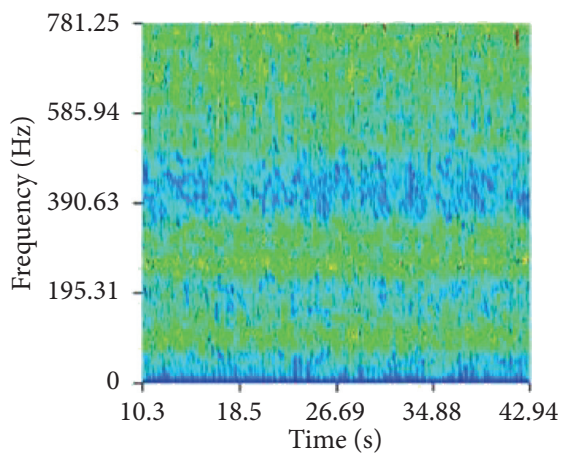

(c)

FIgURE 14: Frequency cloud of vibration time with coaxial drive under the threshing state. (a) $X$ direction. (b) $Y$ direction. (c) $Z$ direction.

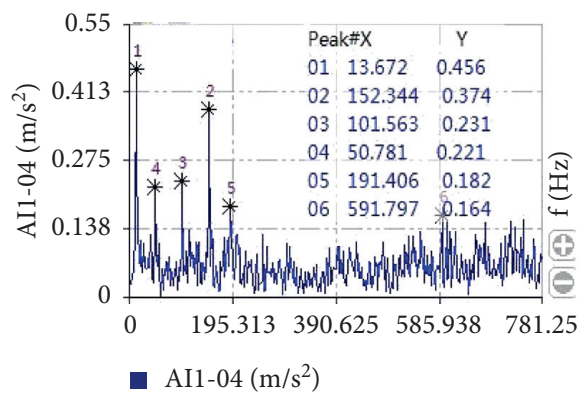

(a)

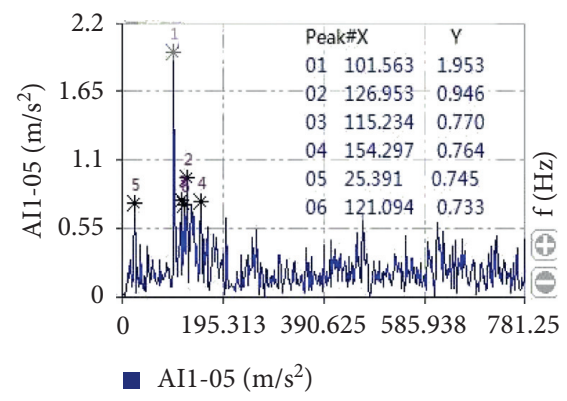

(b)

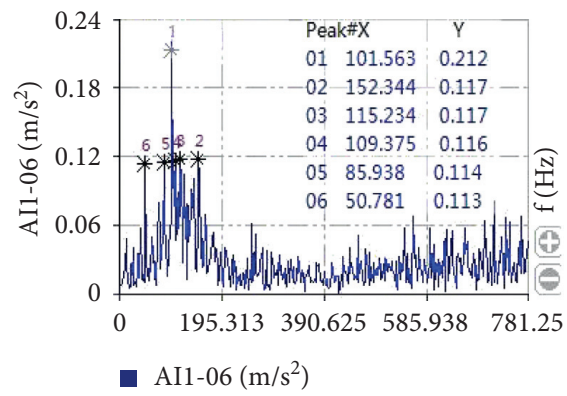

(c)

FIGURE 15: Frequency-domain vibration signals of the bearing seat with coaxial drive under idling state. (a) $X$ direction. (b) $Y$ direction. (c) $Z$ direction. 


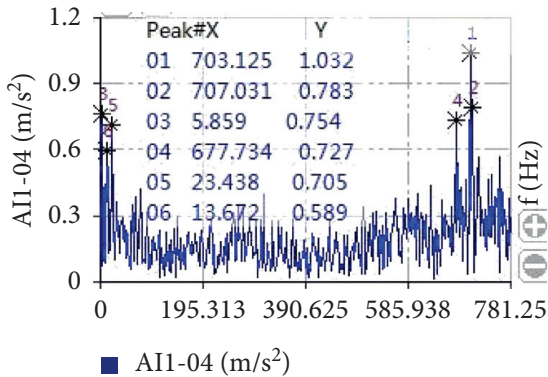

(a)

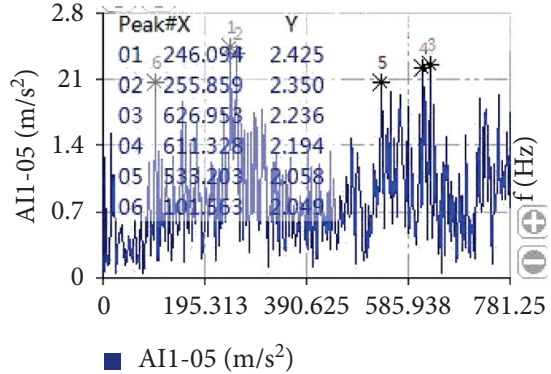

(b)

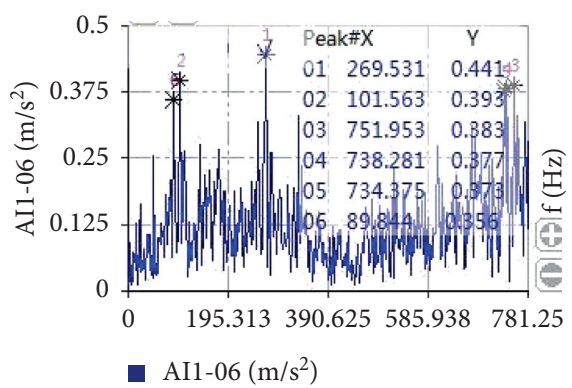

(c)

Figure 16: Frequency-domain vibration signals of the bearing seat with coaxial drive under threshing state. (a) $X$ direction. (b) $Y$ direction. (c) $Z$ direction.

TABLE 7: Vibration signals of the free end of the bearing seat under idling state and threshing state.

\begin{tabular}{lcccccc}
\hline Vibration frequency serial no. & \multicolumn{2}{c}{$\begin{array}{c}\text { Vibration frequency in } X \\
\text { direction }(\mathrm{Hz})\end{array}$} & \multicolumn{2}{c}{$\begin{array}{c}\text { Vibration frequency in } Y \\
\text { direction }(\mathrm{Hz})\end{array}$} & \multicolumn{2}{c}{$\begin{array}{c}\text { Vibration frequency in } Z \\
\text { direction }(\mathrm{Hz})\end{array}$} \\
& Idling state & Threshing state & Idling state & Threshing state & $\begin{array}{c}\text { Idling state } \\
\text { Threshing state }\end{array}$ \\
\hline 1 & 42.969 & 744.141 & 13.672 & 759.766 & 152.344 & 152.344 \\
2 & 777.344 & 755.859 & 738.281 & 755.859 & 13.672 & 720.703 \\
3 & 744.141 & 734.375 & 152.344 & 742.188 & 156.25 & 76.172 \\
4 & 763.672 & 763.672 & 755.859 & 748.047 & 253.906 \\
5 & 667.969 & 714.844 & 744.141 & 728.516 & 259.766 & 429.683 \\
6 & 726.563 & 759.766 & 671.875 & 751.953 & 246.094 & 498.047 \\
\hline
\end{tabular}

vibration frequencies contributed most to the vibration. The excitation frequency $13.672 \mathrm{~Hz}$ was closed to the rotational frequency $11.63 \mathrm{~Hz}$ of the tangential threshing cylinder. And the excitation frequency $152.344 \mathrm{~Hz}$ was 13 times of rotational frequency. There were 12 steel balls in the bearing. The excitation frequency $152.344 \mathrm{~Hz}$ was close to the rotational frequencies of bearing. Main vibration frequency in $Y$ direction and $Z$ direction was $101.563 \mathrm{~Hz}$. So, the main excitation frequencies of the tangential threshing cylinder under idling state were generated by the rotation of the tangential threshing cylinder, steel balls in the bearing, and bolts for connecting the drive shafts. As shown in Figure 16, vibration frequencies of the bearing seat with coaxial drive were high. The reason for the high vibration frequency is that the drive shaft was restricted by the coupling.

Using the same method, the vibration frequency signals of idling state and threshing state at the free end of the bearing seat are shown in Table 7 .

As shown in Table 7, the main excitation frequencies of the free end of the bearing seat in $X$ direction, $Y$ direction, and $Z$ direction were different. At idling state, the excitation frequency $42.97 \mathrm{~Hz}$ in $X$ direction was close to the constraint frequency $41.58 \mathrm{~Hz}$. This excitation frequency was also a main reason for tangential threshing cylinder vibration. The vibration response frequencies were also closely related to the threshing process. The rice-threshing process increased the excitation vibration frequencies. The main excitation frequency $152.34 \mathrm{~Hz}$ was closely related to the constraint frequency $150.50 \mathrm{~Hz}$.

\section{Conclusion}

(1) Mass of straws constantly changed during the threshing process. Remained straw mass along the tangential threshing cylinder reduced gradually. The total eccentric mass attached to 3 rows of threshing bars was $4.05 \mathrm{~kg} / \mathrm{s}$ with a feeding rate of $6 \mathrm{~kg} / \mathrm{s}$. The total eccentric mass attached to 3 rows of threshing bars was less than the remained straw mass $4.934 \sim 4.765 \mathrm{~kg} / \mathrm{s}$ because some straw mass attached to the grid concave. 
(2) The constraint modal and threshing modal values of 12 orders were not corresponding one by one. The fluctuation frequencies of speed and threshing rotational frequency were less than the 1 st constraint modal $(41.58 \mathrm{~Hz})$ and threshing modal $(42.88 \mathrm{~Hz})$. Other intrinsic constraint frequencies were more than the incentive frequency in rice-threshing process. The rotation speed frequency, threshing speed frequency, and fluctuation frequencies would not cause the resonance phenomenon. Rice straw attached to the threshing cylinder would cause modal change of the tangential threshing cylinder.

(3) The vibration amplitude under threshing state increased slightly than under idling state. The vibration amplitude of the free end of the bearing seat along the flow direction of straws increased more obvious than the bearing seat with coaxial drive. In rice threshing state, the vibration amplitude of the free end of the bearing seat along the axial direction of the tangential threshing cylinder increased, which was induced by distribution of the threshing bars. At threshing state, The main excitation frequencies of the tangential threshing cylinder under idling state were generated by the rotation of the tangential threshing cylinder, steel balls in the bearing, and bolts for connecting the drive shafts. At idling state, excitation frequency was also a main reason for tangential threshing cylinder vibration. The ricethreshing process increased the excitation vibration frequencies.

\section{Data Availability}

The data used to support the findings of this study are available from the corresponding author upon request.

\section{Conflicts of Interest}

The authors declare that they have no conflicts of interest.

\section{Acknowledgments}

This research work was supported by the Natural Science Foundation of Jiangsu Province (BK20170553), National Natural Science Foundation of China (51705212), Jiangsu Province "Six Talents Peak" High-Level Talent Project (GDZB-085), Open Fund of Jiangsu Key Laboratory of Agricultural Equipment and Intelligent High Technology (JNZ201912), and project funded by the Priority Academic Program Development of Jiangsu Higher Education Institutions (no. PAPD-2018-87).

\section{References}

[1] X. An, Z. G. Li, M. Zude-Sasse, F. Tchuenbou-Magaia, and Y. Yang, "Characterization of textural failure mechanics of strawberry fruit," Journal of Food Engineering, vol. 282, Article ID 110016, 2020.
[2] J. Fu, Z. Lingua, Z. Chen et al., "Review of grain threshing theory and technology," International Journal of Agricultural and Biological Engineering, vol. 11, no. 3, pp. 12-20, 2018.

[3] L. Zheng, X. Wu, G. Han, H. Li, Y. Zuo, and D. Zhou, "Analytical model for the flow in progressing cavity pump with the metallic stator and rotor in clearance fit," Mathematical Problems in Engineering, vol. 2018, p. 14, 2018.

[4] Z. Tang, X. Y. Li, X. Liu, H. Ren, and B. Zhang, "Dynamic balance method for grading the chain drive double threshing drum of a combine harvester," Applied Sciences.vol. 10, no. 3, pp. 1026-1046, 2020.

[5] S. H. Su and Z. W. Liu, "Hydraulic performance of guide vane mixed-flow pump based on loading distribution," Journal of Drainage and Irrigation Machinery Engineering, vol. 36, no. 12, pp. 1233-1239, 2018.

[6] Y. M. Li, Z. Tang, L. Z. Xu, Z. Zhao, and H. C. Li, "Power analysis and experiment on longitudinal axial-threshing unit test-bench," Transactions of the Chinese Society for Agriculture Machinery, vol. 42, no. 6, pp. 93-97, 2011.

[7] R. K. Tiwari and S. K. Chauhan, "Investigations on effect of cylinder configuration of rectangular spiked tooth thresher on threshing performance of wheat crop," Indian Journal of Agricultural Research, vol. 52, no. 5, 2018.

[8] W. Srison, S. Chuan-Udom, and K. Saengprachatanarak, "Effects of operating factors for an axial-flow corn shelling unit on losses and power consumption," Agriculture and Natural Resources, vol. 50, no. 5, pp. 421-425, 2016.

[9] Z. Tang, Y. M. Li, Z. Zhao, and T. Sun, "Structural and parameter design of transverse multi-cylinders device on rice agronomic characteristic," Spanish Journal of Agricultural Research, vol. 13, no. 4, p. e0216, 2015.

[10] J. Kang, Y. Yuan, H. Liu, J. He, M. Jiang, and P. He, "Load control of threshing cylinder of small-sized harvester based on current detection," Engineering in Agriculture, Environment and Food, vol. 10, no. 2, pp. 150-156, 2017.

[11] J. Zapomel, P. Ferfecki, and P. Forte, "Analysis of the steady state unbalances response of rigid rotors on magnetorheological dampers: stability, force transmission and energy dissipation," International Journal of Applied Mechanics, vol. 6, no. 3, pp. 97-102, 2014.

[12] R. Ebrahimi, M. Esfahanian, and S. Ziaei-Rad, "Vibration modeling and modification of cutting platform in a harvest combine by means of operational modal analysis (OMA)," Measurement, vol. 46, no. 10, pp. 3959-3967, 2013.

[13] L. P. Chai, J. F. Yu, and Y. Li, "Pressure pulsation characteristics in series-parallel centrifugal pump with unequal blade pitch," Journal of Drainage and Irrigation Machinery Engineering, vol. 37, no. 9, pp. 752-757, 2019.

[14] P. Li and H. Xu, "Braking efficiency and stability of chassis braking system of combine harvester: the theoretical derivation and virtual prototype simulation," Mathematical Problems in Engineering, vol. 2019, Article ID 6713231, p. 18, 2019.

[15] V. Talamala, P. R. Kancherla, V. A. R. Basava, and A. Kolakoti, "Experimental investigation on combustion, emissions, performance and cylinder vibration analysis of an IDI engine with RBME along with isopropanol as an additive," Biofuels, vol. 8, no. 3, pp. 307-321, 2017.

[16] S. Koynov, Y. Wang, A. Redere et al., "Measurement of the axial dispersion coefficient of powders in a rotating cylinder: dependence on bulk flow properties," Powder Technology, vol. 292, no. 5, pp. 298-306, 2016.

[17] B. Bai and L. X. Zhang, "Dynamic response of hydro-turbine set shaft system under stochastic hydraulic excitation," 
Journal of Drainage and Irrigation Machinery Engineering, vol. 35, no. 5, pp. 398-403, 2017.

[18] Y. Tang, F. Lin, and Q. Zou, "Dynamical behavior analysis of rubbing rotor system under asymmetric oil film force," Mathematical Problems in Engineering, vol. 2019, Article ID 1253646, p. 16, 2019.

[19] R. Zhu, G. C. Wang, Q. P. Han, A. L. Zhao, J. X. Ren, and X. Xia, "Dynamic characteristics and experimental research of a two-span rotor-bearing system with rub-impact fault," Shock and Vibration, vol. 2019, Article ID 6309809, p. 15, 2019.

[20] Y. Li, T. Ren, J. Zhang, and M. Zhang, "Synchronization of two eccentric rotors driven by one motor with two flexible couplings in a spatial vibration system," Mathematical Problems in Engineering, vol. 2019, Article ID 2969687, p. 13, 2019.

[21] L. Yang, W. Wang, M. Wang, H. Zhang, and M. Hou, "Structural dynamics of corn threshing drum based on computer simulation technology," Wireless Personal Communications, vol. 102, no. 2, pp. 701-711, 2018.

[22] A. Kemzuraite, A. Andriusis, V. Kiniulis, D. Steponavcius, and D. Juknevicius, "Dynamic indicators of a corn ear threshing process influenced by the threshing-separation unit load," Mechanics, vol. 4, no. 24, pp. 412-421, 2018.

[23] Z. Tang, H. T. Zhang, and Y. P. Zhou, "Unbalanced vibration identification of tangential threshing cylinder induced by rice threshing process," Shock and Vibration, vol. 2018, Article ID 4708730, 14 pages, 2018.

[24] H. Dong, Q. Chen, W. Wang et al., "The growth and yield of a wet-seeded rice-ratoon rice system in central China," Field Crops Research, vol. 208, pp. 55-59, 2017.

[25] P. K. Oppong, A. Addo, H. Mao, L. Li, and M. K. Golly, "Comparative evaluation of Japanese rice thresher and locally built thresher," African Journal of Food and Integrated Agriculture, vol. 1, no. 1, pp. 8-14, 2018.

[26] Y. C. Yao, Y. F. Du, Z. X. Zhu, E. R. Mao, and Z. H. Song, "Vibration characteristics analysis and optimization of corn combine harvester frame using modal analysis method," Transactions of the Chinese Society of Agricultural Engineering, vol. 31, no. 19, pp. 46-53, 2015.

[27] O. A. Polushkin, O. O. Polushkin, and I. M. Fofana, "More efficient balancing of rotors," Russian Engineering Research, vol. 37, no. 7, pp. 574-578, 2017.

[28] Z. Tang, Y. M. Li, J. B. Liu, H. Zhang, and Y. W. Li, "Dynamic vibration test and analysis of $4 \mathrm{LZ}-2.5 \mathrm{~B}$ combine harvester cutting table rack in wheat harvesting," International Agricultural Engineering Journal, vol. 26, no. 1, pp. 79-86, 2017.

[29] Z. Tang, Y. M. Li, and C. H. Wang, "Experiments on variablemass threshing of rice in the tangential-longitudinal-flow combine harvester," Journal of Agricultural Science and Technology, vol. 15, no. 4, pp. 1319-1334, 2013.

[30] Z. Tang, Y. Li, X. Li, and T. Xu, "Structural damage modes for rice stalks undergoing threshing," Biosystems Engineering, vol. 186, pp. 323-336, 2019.

[31] O. Morvan and F. Emmanuel, "Model correlation and identification of experimental reduced models in vibroacoustical modal analysis," Journal of Sound and Vibration, vol. 342, pp. 200-217, 2015.

[32] P. Zhou, Q. Zhang, and Z. J. Shuai, "Impact of blade number on fluid-induced vibration in centrifugal pump," Journal of Drainage and Irrigation Machinery Engineering (JDIME), vol. 32, no. 7, pp. 567-571, 2014.

[33] Y. J. Chen, Y. Zheng, H. Kan, H. Zhang, J. Xu, and P. Chen, "Modal analysis of axial-flow pump rotor system in water,"
Journal of Drainage and Irrigation Machinery Engineering, vol. 35, no. 2, pp. 126-132, 2017.

[34] P. Ferfecki, J. Zapoměl, and J. Kozánek, "Analysis of the vibration attenuation of rotors supported by magnetorheological squeeze film dampers as a multiphysical finite element problem," Advances in Engineering Software, vol. 104, no. 1, pp. 1-11, 2017.

[35] G. X. Ma, D. Y. Chen, and Y. S. Wan, "Vibration test of a selfmoving grain combine harvester," Modern Machinery, vol. 2008, no. 2, pp. 59-61, 2008.

[36] W. Weijtjens, J. Lataire, C. Devriendt, and P. Guillaume, "Dealing with periodical loads and harmonics in operational modal analysis using time-varying transmissibility functions," Mechanical Systraws and Signal Processing, vol. 49, no. 1-2, pp. 154-164, 2014.

[37] Y. L. Wang, Y. Zeng, and L. K. Xu, "Shafting vibration model with torsion deformation in shaft of hydro-turbine generator units," Journal of Drainage and Irrigation Machinery Engineering, vol. 37, no. 9, pp. 782-787, 2019. 